\title{
Independence as Relational Freedom
}

\author{
Alan M. S. J. Coffee \\ In Women Philosophers on Autonomy, ed. Sandrine Bergès and Alberto Siani, London: \\ Routledge, 2018, pp. 94-112
}

In spite of its connotations in everyday use, the term independence as republicans understand it is not a celebration of individualism or self-reliance. Instead it embodies an acknowledgement of the importance of personal and social relationships in people's lives and reflects our connectedness rather than separateness. Independence is in this regard a relational ideal. This aspect of the concept of republican freedom as independence has not been widely discussed. Properly understood, however, I shall argue that it is a useful concept in addressing a fundamental problem in social philosophy that has preoccupied theorists of relational autonomy, namely how to reconcile the idea of individual human agency with the inevitable and necessary influence of other people, both directly and indirectly as part of our social environment. I derive my account primarily from Mary Wollstonecraft's work which I believe to have been highly innovative in its appreciation of the effects of social influences on human agency whilst remaining largely overlooked by current republican theorists as a historical source. ${ }^{1}$

My purpose in this chapter is to set out the internal logic of republican independence showing how the individual agent is reconciled to the collective decisions and intentions of the population through the central concept of arbitrariness. I frame my discussion in the context of the particular problem of reconciling social influence and individual agency in oppressive environments, raising the difficult question of how to recognize the profound and pervasive effect that domineering and marginalizing cultural conditions have on subjected people's lives, and on the choices they make, without thereby undermining or diminishing their status as self-governing agents. This is an especially difficult problem for many republicans because freedom is only considered to be undermined or reduced by intentional threats - those threats that can be attributed to the actions and decisions of individual agents, even if indirectly. Impediments that originate in the effects of collective cultural attitudes and social structures are said not to be traceable to individual intentions and are not thereby damaging to freedom. I outline a response that I derive from Wollstonecraft's conception of 
independence showing how republicans can use this ideal to address social and structural forms of domination.

The issue of social domination or oppression has also been one of the motivating problems that have driven the development of the ideal of relational autonomy. This is a subfield within the overall field of autonomy that wrestles with the dilemma outlined above of remaining committed to the importance and possibility of individual agency while acknowledging and seeking to understand the significant impact that social structures and cultural context have on individual autonomous action. ${ }^{2}$ While relational autonomy theorists have at times noted that the republican concept contains some useful insights for their own approach, the two literatures - which have both emerged over more or less the same period over the past two or three decades - have not often been brought together in a sustained manner. ${ }^{3}$ There are several understandable reasons why this might have been so. First, republican writers themselves have often neglected the problem of social oppression. Secondly, the basic concepts of autonomy and freedom, while related and often used to refer to overlapping ideas, are not identical and so the insights of one field do not necessarily translate to the other. A third reason may be that while feminist philosophers have largely driven the development of relational theories of autonomy there has long been a suspicion by many feminists of republicanism given its patriarchal history that has been seen to stifle rather than liberate women as agents (Pateman 2007, Phillips 2000). This stance has diminished somewhat in recent years thanks both to the work of important contemporary women writing as republicans as well as to studies that position Mary Wollstonecraft as a significant political theorist who reconceptualized many parts of the republican framework to accommodate and address feminist concerns. ${ }^{4}$

Drawing on some of these latter republican studies, Catriona Mackenzie has analyzed Wollstonecraft as prefiguring and anticipating the contemporary debate about relational autonomy (2016). I find Mackenzie's arguments both perceptive and persuasive and am in substantial agreement with her position. She makes clear in her discussion that her concern is with how Wollstonecraft foreshadows current work on relational autonomy rather than on Wollstonecraft's specifically republican structures and tools (68). With this in mind, my final purpose in this chapter will be to highlight three particular contrasts in how relational autonomy and independence theories frame their respective approaches to the basic problem of social domination and individual agency. 
Although I am articulating a relational formulation for independence as freedom from arbitrary rule as a relational ideal in its own right, the inevitable backdrop is the extensive literature on relational autonomy. The terms independence, freedom, and autonomy are related but distinct. While they are often conflated (and, as ever in philosophy, there are no fixed definitions of any of these notions) the words are often located within specific literatures and discussions, each having its own concerns and reference points, and drawing upon distinct frameworks and assumptions. There are understandable reasons for this. Autonomy is often understood with reference to Kantian and post-Kantian developments in philosophy while the classical period of republican writings extends from Rome and comes to an end at the end of the late eighteenth century. ${ }^{5}$ In its contemporary form, focusing on nondomination, republican discourse is heavily focused on freedom as a political ideal rather than as a condition of moral agency or as part of a metaphysical account of the self. ${ }^{6}$ Much of the literature on relational autonomy addresses these wider concerns. Mackenzie, for example, grounds her approach in a "social ontology of persons-that is, a conception of persons that emphasizes the role of embodied social practices (including linguistic and cultural practices), social group identities, and historical contingencies in the formation of our individual practical identities" $(2014,21)$ while Jennifer Nedelsky rejects "approaches that treat relations as peripheral rather than central and constitutive" of the human self $(2008,7)$. These are reasonable approaches to important questions, and I find Mackenzie's approach especially illuminating. Nevertheless, I restrict my focus to the political dimension for the sake of clarity. To this extent, as I outline it, independence will be consistent with a range of substantive moral and metaphysical accounts of autonomy, even if its historical progenitors would have taken clear positions on these (Coffee 2016, 2017).

Rather than with definitions, my concern is with the issues that relational theories of freedom and autonomy address. Here autonomy and independence share the same basic sense of self-government or self-legislation, having a common etymology albeit from different roots. The traditional synonym for independence was of a person able to act sui iuris, where the Latin mirrors the Greek for self (sui, auto) and law (iuris, nomos). ${ }^{7}$ I take the idea of selfgovernment as my starting point. Self-government is itself a complex ideal. It connotes an ideal of having the ability to shape the contours of one's own life, taking control from within oneself rather than being directed from outside influences. This contains several separate but internally related aspects. Mackenzie distinguishes three elements of autonomy: selfdetermination ("the freedom and opportunities necessary for determining the direction of 
one's own life"), self-government ("the competences necessary for making authentic decisions about one's life") and self-authorization ("to regard oneself, and to be regarded by others, as having the normative authority" to have the other two capacities) $(2016,80)$. She finds all of these elements in Wollstonecraft's account of independence. I agree but articulate these differently along two dimensions, independence of mind and civil or political independence.

The structure of this chapter is as follows. In the first section, I address some misconceptions about independence. In the second, I identify three distinctive features of the internal logic of freedom as independence that give it a relational character: first, that the person is always located within a community ('free person in the free state'); second that the individual and collective perspectives are connected through the mediating role played by the notion of arbitrariness; and third, that a causal relationship exists linking each person's freedom as independence such that that the dependence of one class of people jeopardizes the independence of the whole community. In section III, I consider the issue of structural domination in which systematic oppressive forms of social and cultural organization combine to undermine independence especially by restricting and distorting the range of background values and concepts that are available in public discourse, and by creating conditions that often lead to marginalized people developing an internalized sense of inferiority and acceptance of their situation.

Independence is a confusing term. According to Nedelsky, independence is an individualistic concept that emphasizes the boundaries that separate people $(1989,2012)$. This individualism, she maintains, is characteristic of liberal thinking which she identifies as being constructed around a notion of what she describes as 'autonomy as independence' in contrast to relational autonomy $(2012,3-8)$. Such an individualistic way of thinking, Nedelsky argues, is both misleading, because these boundaries are artificial, and damaging, because drawing them obscures and undermines the ties between us that make any notion of the individual meaningful. The result is that we are presented with a false choice. "When autonomy is identified with individual independence and security from collective power", she says, "the choice is posed between admitting collective control and preserving autonomy in any given realm of life" (1989, 14; 2012, 126-7). "Such a dichotomy", she adds, "forecloses a whole range of social arrangements - at least to anyone who values autonomy". These arrangements 
are those that would foster and protect the social relationships that make personal freedom possible. Nedelsky regards the high value placed on independence as characteristic of what she calls 'liberal individualism', something she identifies as "the dominant mode of thought", whose ideals inform and permeate the "set of (often unexamined) frameworks and presuppositions that are deep in Anglo-American culture". These features influence the structure of our social, political and legal institutions as well as our background cultural way of thinking $(2012,8,41)$. The effect of the value that is placed on 'autonomy as independence' is that people come to think of themselves as self-contained - often self-made and self-reliant - individuals without appreciating or understanding the role that relationships played in making this quality possible both as an ability and in the options it affords them. Dependence and mutual interdependence are inevitable features of daily life for us all, she argues (26-30). If we both fail to recognize this and even overtly denigrate these aspects of social reality then we can hardly construct the most effective or most just set of institutions and practices within which to live.

Although I believe that Nedelsky overstates her case, I am sympathetic with much of what she says about the dangers of individualism, especially in how it can come to influence the social, conceptual and normative structures of society. I too distance myself from individualism of the sort that she describes. I do not, however, recognize in her description the concept of independence as I use it. Underpinning Nedelsky's critique is a rejection of the idea that autonomy is incompatible with interference from others (2012, 97-9). Rightly, in my opinion, she maintains that interference of certain kinds is necessary for the development of the very capacity to act autonomously. Accordingly, she argues, we should focus on the structure of power relations between people, developing institutions and practices that promote constructive power relations $(2012,64)$. To put this in republican terms, Nedelsky's hostility to the ideal of autonomy as independence is tied to her deeper rejection of the idea of freedom as non-interference, which is the view that freedom is curtailed only and always where there is interference in a person's intended actions. Republicans, too, reject the noninterference definition of freedom, arguing instead for a conception of freedom as nondomination which is precisely an attempt to constrain and restructure power relations. ${ }^{8}$ (This is not to say that she endorses freedom as non-domination. Nedelsky does not discuss this concept in Law's Relations and the structure of freedom as independence from arbitrary power is different from her notion of relational autonomy. $)^{9}$ 
In developing the idea of independence as a relational form of freedom I am drawing on the historical republican tradition. Another source of confusion, therefore, is that there can be no doubt that this tradition's most well-known representatives have understood independence in just these bounded individualistic and self-reliant terms. To name just one, Richard Price a mentor to Wollstonecraft and her close friend - identifies as the paradigm of freemen, the "independent and hardy yeomanry" of the American provinces who were "trained to arms, instructed in their rights, cloathed in homespun... [and] drawing plenty from the ground" (Price 1992, 145). While was such rugged individualism highly prized, dependence was also despised. Dependence in republican discourse was synonymous with servitude in a context where slaves were reviled and shunned. Not only were slaves abject in their inability to stand up for themselves and to take their own decisions but this very condition was said to foster and generate ignoble patterns of behavior such as cowardice, sycophancy and deceit which were regarded as being incompatible with the virtues of the independent citizen-agent (Skinner 2008, Coffee 2014).

In response, I should like to emphasize that these sentiments - the valorizing of the self-made, self-reliant individual and the denigration of those who are regarded as dependent - have no part in the formal meaning of the term independence as I define it (and as I derive it from Wollstonecraft) and neither do they have any place in its internal logic (Coffee 2013, 2014). Indeed, it is as a corrective to these unhelpful historical attitudes, which have become deeply ingrained in republican theorizing, that I have turned to the writings of women and other marginalized writers such as ex-slaves and Reconstruction-era black writing as my primary source of inspiration (Coffee 2017, 2018 forthcoming). Women in the eighteenth century knew what it was like to be always and inescapably dependent on others. However, while writers such as Wollstonecraft sought to escape the clutches of dependence they did not despise or reject the fact of needing care or assistance. The predominant thought was not to achieve an isolated existence but to stand among equals, protected from the abuses of power.

In light of these misconceptions, an inevitable question is why we should continue to use the term rather than discard it in favor of a more apt label such as 'interdependence'. One reason for retaining it echoes Nedelsky's own justification for persevering with the concept of autonomy despite its confusing connotations (2012, 41-5). Independence, like autonomy, is a foundational and indispensable moral, political and social value that is of great importance to both individuals and communities. It is too important an ideal to surrender or lose sight of and the very misconceptions it generates are what make it all the more necessary 
to reconceive. A second reason is that independence is a historically significant term for personal and civic freedom. Although republicans often refer today to 'non-domination', following Pettit, this use represents only a small part of the considerable literature that stretches back to the Roman Republic. There is a danger in breaking the connection with this historic idea that we lose the insights, possibilities and subtleties of this complex ideal. Finally, independence is also Wollstonecraft's own word. For scholars of her work, to replace it with a proxy such as 'interdependence' would distort her meaning.

Wollstonecraft was acutely aware of her state of dependence and self-consciously described her condition, and the condition of all women, as slaves because of their inescapable subjection to male power (Coffee 2013). As a wife she had no legal standing on her own but was instead covered by her husband who represented them both, something she described vividly in her novel Maria. ${ }^{10}$ Even in a happy marriage to a man who would never treat her as less than an equal the brutal fact remained that a wife was wholly in his power and could never act on her own account. In their own marriage Wollstonecraft and Godwin may perhaps have been mutually interdependent (we might suppose) but this does not negate the importance of independence so much as express an additional value to be considered. Wollstonecraft gives two grounds for this. First, she highlights the psychological importance of knowing that she is an equal, an agent in her own right who is a personality separate from others who can make her own decisions and judgements. This does nothing to deny the fact that our lives are intimately and intricately bound up with one another. Rather she argues that true interdependence comes only from a position in which each party starts as an equal morally and legally - with the mutual respect that this requires. ${ }^{11}$

The second part of her argument draws on the old republican saw that we simply cannot rely on the continuing goodwill of those who have unconstrained power over us. Republicans have, for example, always been suspicious of the claim that they had nothing to fear from the king because he would never abuse his power since this said nothing of how his successor might behave. Bonded slaves, too, knew that even though their master might have promised them their liberty when he died, all too often the executor would disregard this when the estate was divided. ${ }^{12}$ So it was with women who entered seemingly loving marriages only for things to change. ${ }^{13}$ Wollstonecraft would not, I believe, accept the alternative rendering 'interdependence' to replace 'independence' where this would obscure or soften the vital protections that independence provides. In emphasizing our connectedness we must not lose 
sight of the real dangers of dependence on arbitrary forces without protection and the ease with which the powerful can take advantage of their dominance while professing mutuality.

Independence in Wollstonecraft's sense does not indicate that one does not need the help of others. Rather what is required is that the resources that a person needs in order to function as an equal in society are available as a matter of right rather than as acts of charity or grace. An elderly person, for example, who is now unable to work remains independent by being entitled to an old age pension, just as a severely disabled person has a right to the appropriate forms of care. It is consistent with independence that a mother of young children either receives support for childcare (if she chooses paid work for example) or has access to an income that allows her to care for her own children (Coffee 2014). Individuals requiring assistance of these kinds should not feel guilty or beholden. Instead, they have an expectation that its provision is an entitlement for anyone considered to be an equal collaborator and member of society. This is not a matter of demanding one's rights but of understanding one's equality. Of course the love and intimacy that so often are part of the caring relationships that are so important in all our lives cannot be compelled by law. But we can seek to secure for each person the means for protection against abuse (Young 1995).

\section{II}

Independence, like autonomy, is an ideal of self-government. This is both an individual and a collective concept, although it is grounded in the concern that individuals should govern their behavior according to their own wills rather than being controlled externally by the wills of others. Two aspects of this definition are important to note. First, control is understood in terms of relationships of power rather than of actual coercion. Secondly, control must be resilient. We are not self-governing if it is by mere chance that we are not the objects of unwarranted interference. Rather we must be beyond its reach. In republican terms, this means that we must be independent of the discretionary (or arbitrary) power that others might wield over us. ${ }^{14}$ This is a matter of our status within a collective body of people rather than of our particular abilities or powers as individuals.

One can discern something of the character of an approach to political theory through its imagery. Within the social contract tradition, for example, the starting point is that of the pre-political individual who consents to be part of a collective body because of the net advantage. Although there is some loss of freedoms in joining the state, overall freedom is 
said to increase. This contrasts with the republican approach within which independence is situated. Rather than building up from the individual towards the political community in its conception of freedom, the republican model starts with the fact of community. The image is that of 'the free man in the free state' (Skinner 2010). Freedom is not compromised or netted off against unfreedom within the state but instead, in Pettit's word, instantiated by it (1997, 106-7). Personal freedom is made possible only in relationship with others and we work from both ends - up from the individual and down from the collective - to derive the meaning of this ideal as well as its parameters and scope. To understand and locate these we have to understand the central role played by the concept of the common good around which the whole of republican independence, and by extension the whole republican framework, is constructed.

Independence is only possible in community with others for the simple reason that outside of society the resilience condition could not be met. People would each be exposed to the potential of unrestrained power from anyone that happened to cross their path. Even lone individuals or hermits are not truly independent in this sense since they cannot escape the danger that groups of bandits might discover their whereabouts and overpower them. Independence on this scale requires a strong force to back it up, which requires the cooperation of others. Freedom is, therefore, a necessarily social ideal. Republicans take the force that enables freedom to be the law. This law inevitably faces a delicate task. If it is to guarantee rather than threaten my independence it must reflect my ideas about what I wish to do. If it does this for me, it must do so for all those others over whom it governs, on pain of being arbitrary for them. The law, therefore, must represent and uphold the people's shared interests, or in other words, their common good. Identifying and agreeing what is in the common good is the primary theoretical and practical concern for republicans. This is the criterion by which the notion of arbitrariness is understood, where arbitrariness is part of the meaning of freedom. The common good is the reference point by which a people distinguish freedom from oppression, or historically, servitude. Anyone whose ideas are not included in the shared ideal of the common good, and who is therefore ruled by a law that does not represent their interests and perspectives, is ruled arbitrarily and thereby unfree.

Having the common good as its focal point, independence is both a sociallydetermined and a necessarily inclusive ideal. By its definition, the idea of the common good of the members - or citizens - used by a political community must reflect the actual ideas and perspectives of all those it claims to represent. While there is scope for republicans to differ 
on the balance between the extent to which the common good is objectively determined by reason or the moral law, or varies with the subjective opinions of the people, republicans are agreed that an ideal of the common good cannot be imposed but must be endorsed by the citizens themselves. It follows that the people must deliberate in an open and accessible manner and discuss their shared objectives, interests and values. This requires both a suitable institutional framework and a population of individuals who are capable of and willing to engage with the process. The role that others play in making our independence possible points to another of its relational features.

As I understand Wollstonecraft, freedom is constituted by three component parts each of which is causally dependent on each of the others: independence, equality and virtue. ${ }^{15}$ To be independent we must be equals within a society in which that equality is respected and protected, which is what is meant by virtue. ${ }^{16}$ If any one of these elements is diminished, it has a corresponding effect in weakening the others. Dependence, for example, introduces inequalities between the powerful and the weak, while inequalities by placing people asymmetrically with respect to the common good weakens people's resolve to behave with virtue. Relationships of both dependence and inequality are said, in the traditional terminology, to corrupt virtue. They do this for both parties to the relationship, for both dominator and dominated alike. The powerful are motivated not to maintain the collective good but to protect their advantage, while the powerless are not in a position to think in a high-minded way but must seek any benefit that they can by whatever means. Each side, therefore, views the other not as a fellow citizen but as a threat and a rival. Significantly, the process of corruption is said to spread from one bilateral case of domination to others as more and more people are drawn into the conflict. Once individuals have lost their commitment to the common good then this affects their behavior in other relationships, particularly where they seek to gain support for their cause from others (a man dominating his wife for example may try to persuade others that this is an acceptable, even good, thing so that he does not stand out).

No less than virtue, the condition of equality is a demanding one. It is not enough that people are equal in some respects but not others because the process of corruption spreads from one sphere of social life to the others. Continuing with the domestic situation, for example, where a wife is dependent on her husband financially then this undermines her independence in other areas of life because she cannot risk displeasing him and losing his goodwill. Legal and political equality mean little if one cannot pay one's bills. Similarly, 
people's economic independence is compromised if they lack the basic legal or political rights to protect their interests. As pockets of inequality and dependence spring up throughout society, so the process of corruption spreads both horizontally, from one bilateral relationship of domination to another, and vertically, to infect the institutions that are responsible for maintaining independence in the state. The process is both relentless and imperceptible, spreading like rust, to use Madame Roland's image, eventually to corrupt the virtue of society as a whole as the moral community is replaced by an arena of competing private interests. ${ }^{17}$ And like rust, the process once started is difficult to arrest or reverse. Each person's freedom, then, is tied to that of everybody else. ${ }^{18}$

We can now see how integral relationships of care are not only to the independence of the individuals who receive support but also to the freedom of the entire community. A person in need of care cannot be dependent in the republican sense because this would introduce a corrupting factor into society that would eventually come to threaten the freedom of us all. This possibly sounds far-fetched. But the numbers involved are considerable. We can think, for example, about how a society treats its elderly population. In the UK there are around 12 million people of state pensionable age which represents some $30 \%$ of the workforce (in the USA this percent is $20 \%$ ). ${ }^{19}$ As people in this age group come to need increasing amounts of care, if they lack adequate resources this can have several effects. Where the costs of caring for one's parents rise, for example, then children are forced to make difficult decisions. They may perhaps be forced to turn to shoddy care homes and they may come to resent the burden and the feelings of guilt that emerge. Trust between generations may then erode, and younger people realizing that they will have to save for themselves become hardened to the plight of others. Low paid care workers can become cynical and alienated and even take out these feelings on those in their care. Once dependence and inequality are introduced then the effects on virtue can quickly start to unravel across different sectors and sections of the population. If the example of the elderly seems a stretch from historic republicanism, the structure of this argument mirrors the classical arguments for why republics should not allow either slavery or monarchy to take root in their societies. ${ }^{20}$

The right to receive appropriate kinds of care and support does not, of course, remove the need for fostering intimate, loving family relations. These are part of the social norms that support independence rather than independence being an ideal that opposes them. If families and other carers need greater support from the state to ensure that the necessary level of 
loving and personalized care can be maintained, then this too is a duty of the state to uphold. ${ }^{21}$ In short, the independence of the carer and the cared for must be prioritized.

\section{III}

A problem that many feminists will have immediately spotted with the model of independence outlined above was its reliance on an ideal of the common good as representative and inclusively defined. Identifying any such ideal would be a problematic undertaking at the best of times but given the long history of marginalization and oppression of women then the prospects seem vanishingly slender. Not only has there been a long history of sexism in republican theory but much of its core terminology - citizen, civic duty, public and private, as well as independence itself - can be seen to have taken on gendered and exclusionary nuances and meanings. ${ }^{22}$ This presents a genuinely challenging obstacle and is effectively an application of a longstanding issue of circularity in republican theory: citizens are only free in a free state, while a state is only free where its citizens are free. In other words, it takes an independence-supporting community to produce independent citizens and yet such a community can only be created by people who are already independent.

A related problem concerns what republicans are to say about women's agency where they live in flawed and non-ideal societies. This issue has sometimes been expressed as the 'agency dilemma' (Khader 2011, Mackenzie 2015, 48). If we accept that social circumstances shape and direct our identities, preferences and capacities, then under oppressive conditions we are confronted with a difficult choice. People in difficult circumstances often make what seem to be bad choices, or at least choices that would not seem to be in their best interests - for example by reducing rather than increasing their overall life options or acting on social stereotypes such as the dutiful housewife whose fulfilment is only through serving her family - rather than authentically choosing for themselves how they want to direct their life. ${ }^{23}$ We then face a troubling choice: do we accept that the choices made by members of the victimized group are autonomous (or independent) or do we "risk impugning [their] agency and opening the door to objectionably paternalistic and coercive forms of intervention in their lives" (Mackenzie 2015, 48)? We also risk constraining the diversity in potentially valuable or legitimate choice and ways of life by judging too harshly those we consider unenlightened or inauthentic. 
I take these problems - the identification of the common good, and how we think of the agency of the oppressed - in turn. ${ }^{24}$ Starting with the first, one of Wollstonecraft's great contributions to republican theory comes in the way that she addresses the use of structural domination. She analyses independence as coming in two parts, both of which are necessary. In order to be free, we must be able to think for ourselves (independence of mind) and be able to act on the outcome of our decisions (political or civil independence). Independence of mind comes in two parts. First, there is the basic capacity for rational thought and selfreflection. Additionally, independent individuals must understand themselves as being both capable of and permitted to think in this way. Both parts are necessary but they should not be conflated. Oppressive social conditions might leave some people's critical capacities intact while leaving them believing that their exercise is 'not for the likes of them'. Political independence in turn entails not only having the requisite equal rights, ample resources and adequate opportunities, but also sufficient social standing. There must be a mutual recognition, or common knowledge, between citizens that they are each legitimate and equal co-members and creators of the shared social and political community.

Wollstonecraft addresses both parts of independence in a holistic account. However, throughout the second Vindication, she makes clear that she considers the gravest threat to women's freedom to be to their independence of mind in both aspects. Rights, for example, can do little to protect or empower those whose minds are vulnerable to being controlled by others. An important part of her solution comes from education. ${ }^{25}$ In addition to formal education a wider social education is required through having the right role models and sources of inspiration and challenge in our lives so that we can develop practical skills and our imaginations. ${ }^{26}$ Macaulay takes the concept of education much further. Every interaction we have with others, she argues, no matter how small or random, has an effect on the development of our personality and beliefs. "Every error thrown out in conversation", she argues, "every sentiment which does not correspond with the true principles of virtue, is received by the mind, and like a drop of venomous poison will corrupt the mass with which it mingles" $(1790,103)$. This points to a highly insidious threat to women's independence of mind, one that comes from the entire structure of background social beliefs, attitudes, practices, habits and values. In a patriarchal society, Wollstonecraft argues, all of these combine to thwart the progress not only of women's intellectual freedom but of men's too since both sexes inhabit the same set of restricted ideas. ${ }^{27}$ 
That people's social background is both inescapable and profoundly shapes their beliefs, character and self-image so deeply need not mean that they cannot still be independent. There are always power structures around us that will coerce and influence us, whether these are laws or simply the wills of other people. The republican response to threats to freedom is not to avoid them or to defeat them. Instead it is to render them non-arbitrary. If other people's wills represent a threat to our own, for example, then the republican solution is to place everyone under a law that restrains all of our behavior. So it is with the social and cultural threat to freedom. Wollstonecraft analyses the problem of a dominating culture using the same basic republican structure. People's inability to reason for themselves, and their subsequent tendency to take ideas on trust or to be influenced by what they read or hear, "makes them all their lives, the slaves of prejudices" $(2014,139) .{ }^{28}$ She means slaves in a literal and formally republican sense of being subject to arbitrary power. That power is in this case cultural. Men enjoy a systematic power advantage - often referred to today as 'male privilege' - over women in virtue of the cultural and conceptual ideas that make up their shared social background. There is, of course, a significant difference between cultural and other sorts of power. Most forms of power - such as economic, political or physical power can be regulated and constrained under appropriate non-arbitrary laws. In the case of a society's cultural background, by contrast, the direction of influence seems to be the other way around. It is culture that influences how we understand what the law means (Coffee, 2015). And while the law is a codifiable body of regulations, culture is open-ended, diffuse and constantly changing.

There is, however, another defining characteristic of non-arbitrariness that the law and the cultural background do share. A non-arbitrary law must be inclusive and representative of the interests and perspectives of all those it governs (on pain of otherwise being nonarbitrary). Since the law is the creation of the people for the protection of their freedom, it must be open to being made, challenged and refined or revised by each citizen. This is something that we can strive to replicate with cultural norms and ideas. We can open up the channels by which ideas and practices are spread so that women's voices and interests can be heard and gain a foothold. This is an enormous undertaking, of course. What is required is, in effect, what Wollstonecraft describes as a "revolution in female manners" (2014, 71, 210, 224). What she has in mind is not feminine behavior and etiquette so much as a radical remaking of the structure of economic, political and social relations in which women interact with each other and with men. What is needed is for women to take part in redefining the role 
of both sexes. The result will be a collaborative remaking of the social background. This is clearly a long term project that Wollstonecraft concedes herself will take generations. But it gives us a blueprint. Creating cultural change, of course, is neither easy nor quick. Wollstonecraft concedes that "it will require a considerable length of time to eradicate the firmly rooted prejudices which sensualists have implanted" $(2014,73)$. Nevertheless, she remains optimistic. It may take time to overcome "the inertia of reason; but, when it is once in motion, fables, once held sacred, may be ridiculed" and the whole edifice can be replaced $(2009,56)$.

If changing a culture and its social structures is the way to bring independence, the question remains as to what we are to say about women who are locked into existing sexist ways of life. Even taking account of the restriction in my focus here to considering independence as a political rather than metaphysical ideal or as an account of moral agency, I do not believe that the issues of denigration and paternalism arise in quite the same way as they do in the field of relational autonomy where they represent a prominent concern (Mackenzie 2016, 69). This stems from the bi-directional nature of independence as an account of the individual and the collective viewed in light of the institutional and cultural structures that organize and regulate their interactions. We cannot single out women in a patriarchal or sexist society as having their independence or agency diminished. In a corrupted society no one emerges unscathed. Men may be in the dominant position, but they are no less dependent on a background that impairs their ability to reflect and think critically. Even "men of the greatest abilities", Wollstonecraft argues "have seldom had sufficient strength to rise above the surrounding atmosphere" $(2014,68)$. The reason is twofold. First, their thinking is constrained by the same distorted and false ideas as women's and secondly, people in a dominant position come to have a particularly warped sense of reality as the information they receive is filtered to reinforce their sense of superiority. And so, just as "the page of genius [i.e. Rousseau] has always been blurred by the prejudices of the age", she concludes, "some allowance should be made for a sex, who like kings, always see things through a false medium".

In arguing that both men and women are equally affected, I in no way mean to diminish the psychological and social harms that are done to oppressed and marginalized women. An internalized sense of inferiority or inadequacy can be crippling and the accompanying dangers of abuse, neglect and poverty cannot be overstated. My point is only that the subordinate party is never to be denigrated since dependent relationships always 
affect both parties - dominator and dominated - as well as the society that permits them. That some women are more onerously burdened remains a collective problem to resolve and the relevant resources must be made available to enable those who are dominated to come to be independent in as many respects as possible.

Does this, finally, mean that the state can intervene in dependent people's lives? We must remember, first, that every member of society - all citizens - has a duty to be sufficiently independent. Willful dependence, no less than oppressed dependence, affects us all through the same set of corrupting processes. Some forms of life - the oft-cited 'happy slave', the stereotypically submissive, traditional wife to use Oshana's examples - will be incompatible with maintaining a free society $(2006,84)$. This is the flip side of the relational nature of independence which while it liberates also constrains, albeit non-arbitrarily. We affect others through our relationships just as they affect us and so we all have an obligation to behave in non-damaging ways. Some life choices will be ruled out. A young woman, for example, who marries without completing her education and then lives a subservient and highly sheltered life, uncritically reflecting the opinions of others around her, would not be independent. On the republican account, if such a way of life were replicated on a large scale throughout society, this would have a corrupting effect on virtue that would be harmful to the free character of the state.

This does not, however, open the door to state paternalism. Any intrusive action would not be for the good of the women concerned, as if government knows best. Intervention can only be justified if it is non-arbitrary which means it must be for the acknowledged common good where this is the outcome of a negotiation in which the affected women have a voice. Of course, in cases of subservience the targets of any action might not want a voice or be equipped to exercise it. In this case, the state may act only as far as is necessary to prevent the corruption of virtue so that as far as possible the relevant women's lives are respected consistently with the conditions of basic independence. The result should be that a wide range of life-options are possible and in many cases, such as with women who choose to raise children without also engaging in paid labor, the rest of society must recognize its value and provide the necessary support to make it possible consistently with independence. 


\section{IV}

Although I should very much have liked to locate independence as a relational ideal within the wide range of alternative accounts of autonomy on this issue, the restrictions of space mean that such a dialogue must wait. Instead, I have demonstrated that independence, especially as Wollstonecraft understood it, is a distinctive relational ideal that is both substantial in its own right and that can engage with wider discourses on social and structural forms of oppression. I have done this by articulating three characteristic features derived from the republican understanding of the causal relationship between personal and collective freedom. The resulting conception addresses several concerns that motivate relational autonomy theorists, including the way that it retains a commitment to the normative value of individual persons while remaining responsive to the fact of human vulnerability and acknowledging the complex ways in which people are socially, historically, and culturally embedded (Mackenzie, 2014, 21-2). Seen in this light, I hope the door is now open for a fruitful engagement by republicans and Wollstonecraftians in this wider literature.

\footnotetext{
${ }^{1}$ Wollstonecraft is growing in importance as a republican (See the articles by Bergès, Coffee, Halldenius, James, and Pettit in Bergès and Coffee 2016, also Halldenius 2015). Outside of a relatively small literature, however, Wollstonecraft's presence in republican discourse is dwarfed by the standard canon of male historical sources and references to her are scanty. ${ }^{2}$ See the editors' introduction to Mackenzie and Stoljar (2000) and several of the chapters included. Also Mackenzie 2016.

${ }^{3}$ Marina Oshana (2006) briefly compares Pettit's model of freedom as non-domination with her own conception of autonomy, for example, concluding that while it is necessary nondomination is narrower and therefore insufficient for autonomy, p. 153-4.

${ }^{4}$ See for example Laborde (2008) as well as the scholars listed in footnote 1 above.

${ }^{5}$ There are of course important overlaps. Wollstonecraft for example is likely to have had some familiarity with Kant's work. Like Kant, she also drew extensively on Rousseau's work and shows some echoes of Kantian ideas in her own work (Bergès 2011, 78; Halldenius 2007, 79)

${ }^{6}$ This comes with a heavy caveat. Pettit makes an explicit and elaborate connection between his political, moral and agency-related work (2007). Historically, Wollstonecraft was clearly concerned with these matters and Macaulay's work on moral agency and the metaphysics of the self is extensive (Macaulay 1783).

${ }^{7}$ This use derived from the classifications in Roman Law. See, for example, Gaius (Book I, $\S$ 48), "Another division in the law of Persons classifies men as either dependent [alieni iuris] or independent [sui iuris]" (1904, p. 75). See also Wirszubski 1968, p. 1. The convention of using independence and sui iuris interchangeably is found frequently throughout the history of republican writing.

${ }^{8}$ I use freedom as non-domination interchangeably with independence here although my preference is almost always to use the historical term independence unless it is confusing not to do so. As I reconstruct Wollstonecraft's idea of independence there are several differences
} 
between her use and Pettit's contemporary notion of freedom as non-domination (Coffee 2016, 2017).

${ }^{9}$ I do not develop this comparison with Nedelsky further since my aim in this section is only to clear up some misconceptions about the nature of independence itself.

10 "A wife" Wollstonecraft describes, is “as much a man's property as his horse, or his ass, she has nothing which she can call her own... and the laws of her country - if women have a country - afford her no protection or redress" (2005, 80-1).

11 Wollstonecraft discusses the need for equality and reciprocity in marriage in both Vindications. "Affection in the marriage state" for example "can only be founded on respect" (1995, 22). See also 2014 (55-9).

${ }^{12}$ See Frederick Douglass's story of Aunt Katy (2003, 135-143).

${ }^{13}$ This is a central premise of Wollstonecraft's novel Mary: A Fiction (2008).

${ }^{14}$ I set out my understanding of republican freedom more fully in Coffee 2013 and 2014.

15 The tripartite analysis is neither unique to me nor to Wollstonecraft. Lena Halldenius (2007) uses the same terms as applied to Wollstonecraft although her analysis differs from mine. She also refers to independence as a relational ideal although she does not analyse this term in detail (2015, 28-9). Although I discuss the tripartite structure in Wollstonecraft's work, we also find it in many other writers of the period including Catharine Macaulay and Richard Price (Coffee 2017, 2013).

${ }^{16}$ Virtue is a complex and constantly changing concept. Although it may often have moralised and utopian or other-worldly connotations, all that is formally necessary for virtue is that a person behaves in ways that maintain the integrity and stability of the free republic. On my own account all that is necessary is that people make use of public reason in their deliberations and respect the outcome but I accept that richer notions are possible. See Coffee 2016 (in the context of Wollstonecraft) and 2017 (in the context of Macaulay).

17 "The rust of barbarity covers their proud masters and ruins them together. The poisoned breath of despotism destroys virtue in the bud" (in Bergès 2015, 111).

${ }^{18}$ This is a point Wollstonecraft reinforces in her introduction to her Vindication, arguing that her "main argument" for the rights of women is that a dependent woman "will stop the progress of knowledge, for truth must be common to all, or it will be inefficacious with respect to its influence on general practice" $(2014,22)$.

${ }^{19}$ http://www.pensionspolicyinstitute.org.uk/pension-facts/pension-facts-tables/table-1demographics (accessed 31 July, 2017); https://www.statista.com/statistics/457822/share-ofold-age-population-in-the-total-us-population/ (accessed: 31 July, 2017)

${ }^{20}$ See Coffee (forthcoming) for a version of this argument developed by Frederick Douglass.

${ }^{21}$ See Coffee 2014 on maternity rights and Wollstonecraft.

${ }^{22}$ A great deal has been written on this subject. See Pateman (1990, 3-15) for a classic discussion and Hirschmann (2008, 1-28) for a more recent treatment. See also Coffee 2015, 52-6.

${ }^{23}$ For a discussion of this problem in the context of Wollstonecraft see Bergès 2011.

${ }^{24}$ The more general question of republican circularity is beyond my scope but I accept that it remains an issue for republicans.

${ }^{25}$ In the very first paragraph of her introduction to the Vindication, Wollstonecraft identifies "the neglected education of my fellow creatures [as] the grand source of the[ir] misery", adding that "women in particular, are rendered weak and wretched by a variety of concurring causes [that originate in] a false system of education" $(2014,29)$.

26 "Men, in their youth, are prepared for professions, and marriage is not considered as the grand feature in their lives; whilst women, on the contrary, have no other scheme to sharpen their faculties" $(2014,87)$. 
${ }^{27}$ If woman "be not prepared by education to become the companion of man, she will stop the progress of knowledge, for truth must be common to all, or it will be inefficacious with respect to its influence on general practice" $(2014,22)$.

${ }^{28}$ Here she builds on the same argument made by Macaulay who concludes that it "proves man to be the slave of custom and of precept" $(1790,169)$. I discuss this in detail in Coffee 2013.

\section{References}

Bergès, Sandrine. 2011. "Why Women Hug their Chains: Wollstonecraft and Adaptive Preferences". Utilitas 23: 72-87.

2015. “A Republican Housewife: Marie-Jeanne Phlipon Roland on Women's Political Role”, Hypatia 31: 107-22.

Bergès, Sandrine, and Coffee, Alan, eds. 2016. The Social and Political Philosophy of Mary Wollstonecraft. Oxford: Oxford University Press.

Coffee, Alan. 2018, “A Radical Revolution in Thought: Frederick Douglass on the Slave's Perspective on Republican Freedom". In Radical Republicanism: Recovering the Tradition's Popular Heritage, edited by Bruno Leipold, Karma Nabulsi and Stuart White. Oxford: Oxford University Press (forthcoming).

2017. "Catharine Macaulay's Republican Conception of Social and Political Liberty". Political Studies, DOI: https://doi.org/10.1177/0032321716686991.

2016. "Freedom, Diversity and the Virtuous Republic". In The Social and Political Philosophy of Mary Wollstonecraft, edited by Sandrine Bergès and Alan Coffee, 183200. Oxford: Oxford University Press.

— 2015. "Two Spheres of Domination: Republican Theory, Social Norms and the Insufficiency of Negative Freedom". Contemporary Political Theory 14: 45-62.

_ 2014. "Freedom as Independence: Mary Wollstonecraft and the Grand Blessing of Life”. Hypatia 29: 908-924.

_ 2013. "Mary Wollstonecraft, Freedom and the Enduring Power of Social Domination". European Journal of Political Theory 12: 116-35.

Douglass, Frederick. 2003. My Bondage, My Freedom. London: Penguin.

Gaius. 1904. Institutes of Roman Law. Edited by A. H. J. Greenidge. Oxford: Clarendon Press.

Halldenius, Lena. 2007. "The Primacy of Right. On the Triad of Liberty, Equality and Virtue in Wollstonecraft's political thought", British Journal for the History of Philosophy 15: 75-99. 
2015. Mary Wollstonecraft and Feminist Republicanism, London: Pickering \& Chatto.

Hirschmann, Nancy. 2008. Gender, Class, and Freedom in Modern Political Theory. Princeton: Princeton University Press.

Khader, Serene. 2011. Adaptive Preferences and Women's Empowerment. Oxford: Oxford University Press.

Laborde, Cécile. 2008. Critical Republicanism: The Hijab Controversy and Political Philosophy. Oxford: Oxford University Press.

Mackenzie, Catriona. 2014. "Three Dimensions of Autonomy: A Relational Analysis" in Autonomy, Oppression, and Gender, edited by Andrea Veltman and Mark Piper, 1541.Oxford: Oxford University Press.

— 2015. "Responding to the Agency Dilemma: Autonomy, Adaptive Preferences, and Internalized Oppression”. In Personal Autonomy and Social Oppression, edited by Marina Oshana, 48-67. New York: Routledge.

_ 2016. "Mary Wollstonecraft: An Early Relational Autonomy Theorist?”. In The Social and Political Philosophy of Mary Wollstonecraft, edited by Sandrine Bergès and Alan Coffee, 67-91. Oxford: Oxford University Press.

Mackenzie, Catriona, and Stoljar, Natalie, eds. 2000. Relational Autonomy: Feminist Perspectives on Autonomy, Agency, and the Social Self. Oxford: Oxford University Press.

Macaulay, Catharine. 1783. A Treatise on the Immutability of Moral Truth. London: A. Hamilton.

1790. Letters on Education. With Observations on Religious and Metaphysical Subjects. London: C. Dilly.

Nedelsky, Jennifer. 1989. "Reconceiving Autonomy: Sources, Thoughts, and Possibilities". Yale Journal of Law and Feminism 1: 7-36.

2011. Law's Relations: A Relational Theory of Self, Autonomy, and Law. Oxford: Oxford University Press.

Oshana, Marina. 2006. Personal Autonomy in Society. Aldershot: Ashgate.

Pateman, Carole. 1990. The Disorder of Women. Cambridge: Polity Press.

_ 2007. "Why republicanism?” Basic Income Studies 2: 1-6.

Pettit, Philip. 1997. Republicanism: A Theory of Freedom and Government. Oxford: Oxford University Press. 
2007. "Joining the Dots", Common Minds: Themes from the Philosophy of Philip Pettit, edited by M. Smith, H. G. Brennan, R. E. Goodin and F. C. Jackson, 215-344. Oxford: Oxford University Press.

Phillips, Anne. 2000. "Feminism and Republicanism: Is this a Plausible Alliance?". The Journal of Political Philosophy 8: 279-293.

Price, Richard. 1992. Political Writings, edited by D. O. Thomas. Cambridge: Cambridge University Press.

Skinner, Quentin. 2008. "Freedom as the Absence of Arbitrary Power". In Republicanism and Political Theory, edited by Cécile Laborde and John Maynor, 83-101. Oxford: Blackwell Publishing.

_ 2010. "On the Slogans of Republican Political Theory", European Journal of Political Theory 9: 95-102.

Wirszubski, Chaim. 1968. Libertas as a Political Idea at Rome. Oxford: Oxford University Press.

Wollstonecraft, Mary. 1995. "A Vindication of the Rights of Men " in A Vindication of the Rights of Men and a Vindication of the Rights of Woman, edited by Sylvana Tomaselli. Cambridge, UK: Cambridge University Press.

2005. Maria, or the Wrongs of Woman. New York: Dover Press.

2008. Mary: A Fiction. London: Dodo Press.

— 2009. Letters written in Sweden, Norway, and Denmark, Oxford: Oxford University Press.

2014. A Vindication of the Rights of Woman, edited by Eileen Hunt Botting. London, Yale University Press.

Young, Iris Marion. 1995. "Mothers, Citizenship, and Independence: A Critique of Pure Family Values". Ethics 105: 535-556. 